JSCMT

Journal of Sustainable Construction

Materials and Technologies

J. Sustain. Construct. Mater. Technol. 3(2) (2018) 212-220
Journal of Sustainable Construction Materials and Technologies

http://www.eds.yildiz.edu.tr/jscmt

\title{
Investigation of Waste Products of Boron and Metakaolin Utilizes
}

\author{
Mikhail Mushurov ${ }^{1,}$, Orhan Canpolat ${ }^{1}$, Mucteba Uysal ${ }^{2}$, \\ Mukhallad M. Al-mashhadani ${ }^{1}$, Yurdakul Aygörmez ${ }^{1}$ \\ ${ }^{l}$ Yildiz Technical University, Faculty of Civil Engineering, Civil Engineering Department, \\ Davutpasa Campus, Istanbul, Turkey \\ ${ }^{2}$ Istanbul University, Engineering Faculty, Civil Engineering Department, \\ Avcilar campus, Istanbul, Turkey
}

Received February 2, 2018; accepted April 4, 2018

\begin{abstract}
This paper is concerned with investigation of waste products of boron and metakaolin utilizes in cement mortar. Application of waste products leads to minimization of gross cement amount in mortar production which helps to decrease $\mathrm{CO} 2$ emissions caused by manufacture of cement and recycle byproduct waste materials. Along with supplementary materials, application of $1 \%$ Polydos TS14 solution was investigated. Physical properties such as compressive and flexural strength at age of 2,7 and 28 days were determined and compared with reference mixture. The results showed that cement replacement materials had affected mechanical properties, although addition of TS14 partially amortized those negative effects. The use of colemanite at the concentration over 7 wt.\% showed unacceptably low compressive and flexural strength performances. Also, replacement of Portland cement by $30 \mathrm{wt} . \%$ metakaolin showed poor strength. The mixes with TS14 solution showed notable enhancement of compressive and flexural strength. The most adequate proportions for each of supplementary materials have been designed.
\end{abstract}

Keywords: Mortar; Colemanite; Boron; Metakaolin; Polydos TS14

\section{INTRODUCTION}

Cement is a fine powder which has good binding properties. Cement is the most important artificial construction material. Its production has great significance on today's construction sector [2]. However, manufacture of cement

\footnotetext{
* Corresponding author.

E-mail address: mushurov.m.s@ gmail.com (Mikhail Mushurov)
} 
must meet new and higher demands. Sustainability in terms of construction is very important to the environment of our planet. A sustainable structure is developed to ensure that its total impact on environment over the lifespan, including its use and recycle will be minimal.

In order to accomplish it, sustainable construction materials should be produced with use of recycled materials, sound enough to resist under the loads and be produced with little waste. Sustainable construction materials have a small impact on the Earth environment. Towards this goal, colemanite and metakaolin fine waste materials have been investigated in different proportions along with TS14. Cement based mortar is a sustainable solution for construction, since it helps utilizing of by-products of other industries and obtains unique properties such as higher resistance to Alkali-Aggregate reaction [2].

With regard to its composition, obtained mortar is a sensitive mix, highly dependent on the chemical characteristics of substituent materials. It was observed that substitution of $3 \mathrm{wt} . \%$ colemanite gives mortar extra workability and extends its setting time. Use of TS14 which is a high range water reducer and superplasticizer provides shorter setting and hardening time to all figured batches [3].

The compressive and flexural strength of hardened prisms measured after certain days of curing (2, $7 \& 28$ days). High performance hyper plasticizing concrete admixture Polydos TS 14 which is a polycarboxylate based, new generation super plasticizing concrete admixture is developed for the ready-mix concrete and mortar that require high early strength, significant reduction in the amount of water and excellent workability was used in amount of $1 \%$ by weight of binder.

Chemical admixture TS 14 is used by adding into the mixture water of concrete or directly mixing into the fresh low-slump concrete. It is used in order to increase amount of supplementary materials without harming the strength of mortar, and ensure the early strength of samples. Also it helps to obtain lowest practical water-cement ratio [4].

Colemanite is knows as a borate ore. Colemanite which is figuring is this study has chemical properties represented in Table 1.

Table 1. Chemical composition of colemanite (\%).

\begin{tabular}{|c|c|c|}
\hline Chemical Composition & $\%$ & $40,05 \pm 0,5$ \\
\hline $\mathrm{B}_{2} \mathrm{O}_{3}$ & $\%$ & $27,00 \pm 1,0$ \\
\hline $\mathrm{CaO}$ & $\%$ & $4,00-6.00$ \\
\hline $\mathrm{Si} \mathrm{O}_{2}$ & $\%$ & 0,60 \\
\hline $\mathrm{SO}_{4}$ & $\mathrm{ppm}$ & 35 \\
\hline $\mathrm{As}$ & $\%$ & 0,08 \\
\hline $\mathrm{Fe}_{2} \mathrm{O}_{3}$ & $\%$ & 0,40 \\
\hline $\mathrm{Al}_{2} \mathrm{O}_{3}$ & $\%$ & 3,00 \\
\hline $\mathrm{MgO}$ & $\%$ & 1,50 \\
\hline $\mathrm{SrO}$ & $\%$ & 0,50 \\
\hline $\mathrm{Na}_{2} \mathrm{O}$ & $\%$ & 25,00 \\
\hline L.O.I. & $\%$ & 1,00 \\
\hline $\mathrm{Moisture}$ & ton $/ \mathrm{m}^{3}$ & 1,00 \\
\hline Bulk Density & & \\
\hline & & $\%$ \\
\hline
\end{tabular}

Turkey takes a leading role in boron manufacturing, its global share equals to $47,2 \%$ from worldwide. Colemanite is a by-product of boron refinery, it practically has no application in any manufacture branch. Due to that reason, it is landfilled or disposed to the environments as a waste material. In the recent decade, scientists are conducting plentiful of researches in order to help its recycling. One way of colemanite recycling is its usage as a supplementary material 
in mortar and concrete industries. In respect to grain size of colemanite particle, it can be used as a filler material too [5]

The influence of Colemanite supplementary on the early age properties, compressive strength and workability was studied by [3]. It was discovered that colemanite was technically feasible to be utilized in mortar and together with positive impact on environment, there is financial benefit and high workability taking place [8].

The role of metakaolin (MK) on the strength, water absorption, permeability, fresh and hardened properties \& its fineness \& content in mortar was studied by [6]. Chemical composition of metakaolin represented on (Table 2). It was found that $20 \% \mathrm{MK}$ content gave long term strength, decrease in water absorption by capillary action \& higher permeability resistance. The compressive strength of mortar also decreased with the increase in the Metakaolin amount and with the reduction of its finesses. According to [9] 10-15\% metakaolin substitution found as an optimal. Also, M. Narmathal et al. found the best amount of metakaolin as 15\% [9]. The reactivity of metakaolin is depended upon the amount of kaolinite in the raw clay material [10].

Table 2. Chemical composition of metakaolin (\%).

\begin{tabular}{|c|c|}
\hline Chemical Composition & $\%$ \\
\hline $\mathrm{SiO}_{2}$ & 56,10 \\
\hline $\mathrm{Al}_{2} \mathrm{O}_{3}$ & 40,23 \\
\hline $\mathrm{Fe}_{2} \mathrm{O}_{3}$ & 0,85 \\
\hline $\mathrm{TiO}_{2}$ & 0,55 \\
\hline $\mathrm{CaO}$ & 0,19 \\
\hline $\mathrm{MgO}$ & 0,16 \\
\hline $\mathrm{K}_{2} \mathrm{O}$ & 0,51 \\
\hline $\mathrm{Na}_{2} \mathrm{O}$ & 0,24 \\
\hline L.O.I $1000{ }^{\circ} \mathrm{C}$ & 1,10 \\
\hline
\end{tabular}

For this study, mixes containing 10\%, 20\%, 30\%, 40\% and 50\% of metakaolin have been studied and the most appropriate percentages have been chosen as $20 \%$ and $30 \%$.

The effect of Polydos TS 14 (SP), curing conditions and water-to-cement (w/c) ratio on the mechanical properties of mortar was studied in current case. It was found that introduction of super plasticizers into mortar mixes improved their workability and mechanical properties. The flexural and compressive strengths of mortar increased, as compared to control batch. This paper focuses on the mechanical properties of cement based mortar with mineral admixtures such as colemanite \& metakaolin and high performance admixture and summarizes the outcomes of the research.

\section{Experimental Setup}

The cement mix proportions used in this study for casting the test specimens are represented in Table 3. An experimental program was conducted in order to evaluate compressive strength and flexural strength of different mortar types having different water cement ratio based on ingredients used. The various materials used during the experiment in producing batches, as Ordinary Portland Cement 42,5R, standard Rilem sand, colemanite mined in Turkey, metakaolin and hyper plasticizing concrete admixture Polydos TS14. These materials conformed to the relevant British Standard (BS 197-1) [1]. The specimens used for flexural test are 40x40x160mm prisms, after flexural test conducted, two chunks 40x40x80mm tested for compressive strength. Batches, where TS 14 included, were maintained with lower water cement ratios, due to hyper plasticizing property of used chemical [7]. 
Twelve different combinations of binders were prepared. Combinations are given in table based on the preliminary conducted tests, the best ratios have been decided. For the colemanite, the total substitution ratio should not exceed $7 \%$ from cement weight. For metakaolin, the ratio should not exceed 30\% from cement weight. Mass of super plasticizer determined from a relevant specification document [4].

The sand, pozzolanic materials, water/binder ratio and Super-plasticizer dosage were selected based on results obtained from testing trial mixes. For some batches it become necessary to increase the water/binder ratio, since the mix was very stiff or loose. For mixes where TS 14 applied, water/binder ratio is less since admixture provides extra plasticity.

Table 3. Mixture Proportions or Details of the Investigated Mixes

\begin{tabular}{|c|r|r|c|c|c|c|c|c|c|c|c|}
\hline \multirow{2}{*}{ Mix ID } & \multicolumn{2}{|c|}{ Cement } & Sand & \multicolumn{2}{|c|}{ Colemanite } & \multicolumn{2}{c|}{ Metakaolin } & \multicolumn{2}{c|}{ Water } & \multicolumn{2}{c|}{ TS 14 (SP) } \\
\cline { 2 - 14 } & $\boldsymbol{\%}$ & $(\mathbf{g})$ & $(\mathbf{g})$ & $\mathbf{\%}$ & $\mathbf{( g )}$ & $\mathbf{\%}$ & $\mathbf{( g )}$ & w/c ratio & $(\mathbf{g})$ & $\mathbf{\%}$ & $(\mathbf{g})$ \\
\hline PC & 100 & 450 & 1350 & 0 & 0 & 0 & 0 & 0.5 & 225 & 0 & 0 \\
\hline PC5C & 95 & 428 & 1350 & 5 & 22.5 & 0 & 0 & 0.5 & 225 & 0 & 0 \\
\hline PC7C & 93 & 419 & 1350 & 7 & 31.5 & 0 & 0 & 0.5 & 225 & 0 & 0 \\
\hline & & & & & & & & & & & \\
\hline PCSP & 100 & 450 & 1350 & 0 & 0 & 0 & 0 & 0.4 & 203 & 1 & 4.5 \\
\hline PC5CSP & 95 & 428 & 1350 & 5 & 22.5 & 0 & 0 & 0.4 & 203 & 1 & 4.5 \\
\hline PC7CSP & 93 & 419 & 1350 & 7 & 31.5 & 0 & 0 & 0.4 & 203 & 1 & 4.5 \\
\hline & & & & & & & & & & & \\
\hline PC20M & 80 & 360 & 1350 & 0 & 0 & 20 & 90 & 0.5 & 225 & 0 & 0 \\
\hline PC30M & 70 & 315 & 1350 & 0 & 0 & 30 & 135 & 0.6 & 270 & 0 & 0 \\
\hline & & & & & & & & & & & \\
\hline PC20MSP & 80 & 360 & 1350 & 0 & 0 & 20 & 90 & 0.5 & 225 & 1 & 4.5 \\
\hline PC30MSP & 70 & 315 & 1350 & 0 & 0 & 30 & 135 & 0.5 & 225 & 1 & 4.5 \\
\hline & & & & & & & & & & & \\
\hline PC5C20M & 75 & 338 & 1350 & 5 & 22.5 & 20 & 90 & 0.5 & 225 & 0 & 0 \\
\hline PC5C20MSP & 75 & 293 & 1350 & 5 & 22.5 & 20 & 90 & 0.5 & 225 & 1 & 4.5 \\
\hline
\end{tabular}

\subsection{Results and Discussion}

The results of the compressive strength test conducted on samples containing different combinations of Colemanite, Metakaolin and SP are presented in Table 4 and Fig.1-4. Notable that compressive strength of reference mix did not reach minimal recommended compressive strength value as $42,5 \mathrm{MPa}$ at $28^{\text {th }}$ day, its strength $35.8 \mathrm{MPa}$ or $18.74 \%$ lower. This might be because of undue quality of used tap water. Still, obtained compressive strength is taken as a reference value. As it is observed, compressive strength decreasing as colemanite content increases. Addition of $1 \%$ Polydos TS14 increased compressive strength on almost 20.2\% to 43,0 MPa comparing to the reference batch. 


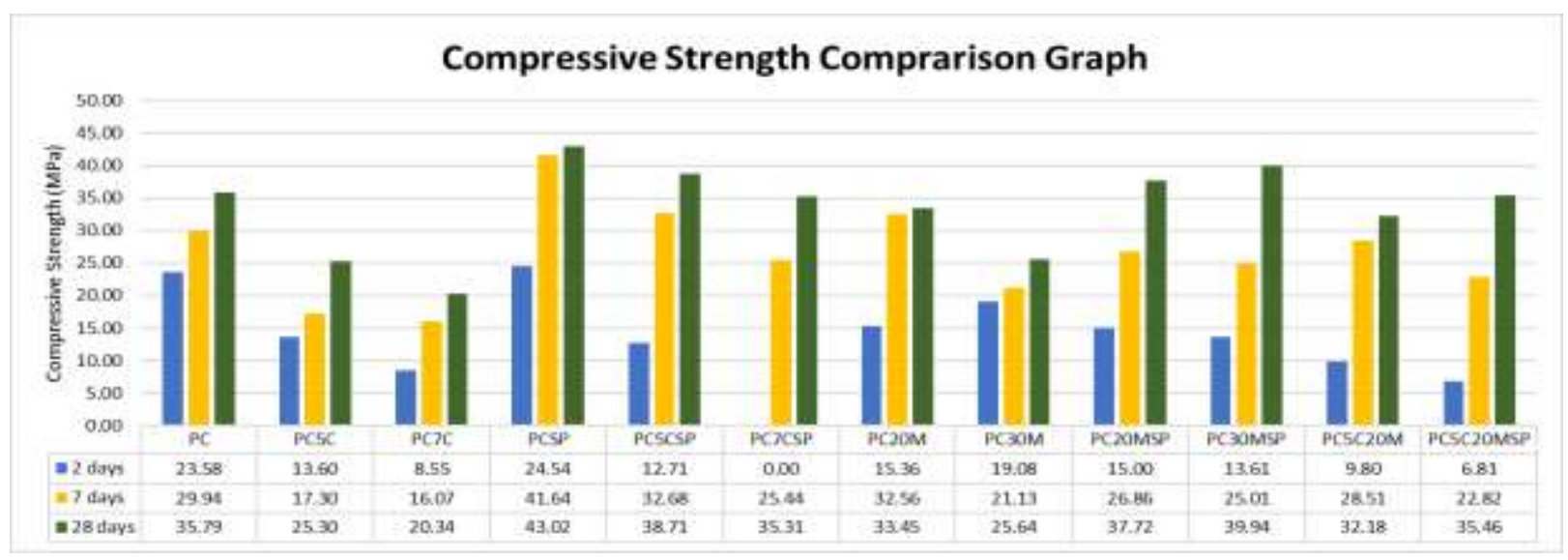

Figure 1. Compressive Strength Comparison

Explicit comparison charts are given in Fig. 2-4:

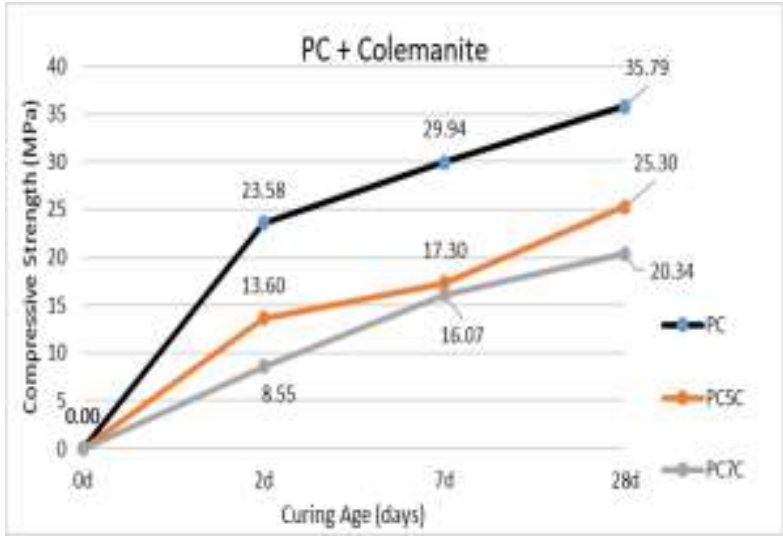

Fig. 2a Compressive Strength of PC and Colemanite at 2, 7, 28 days

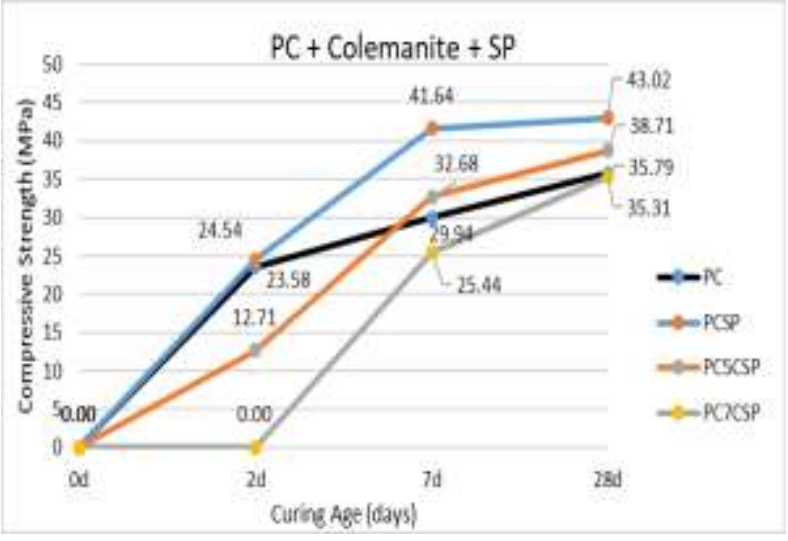

Fig. 2b Compressive Strength of PC, Colemanite and SP at 2, 7, 28 days 


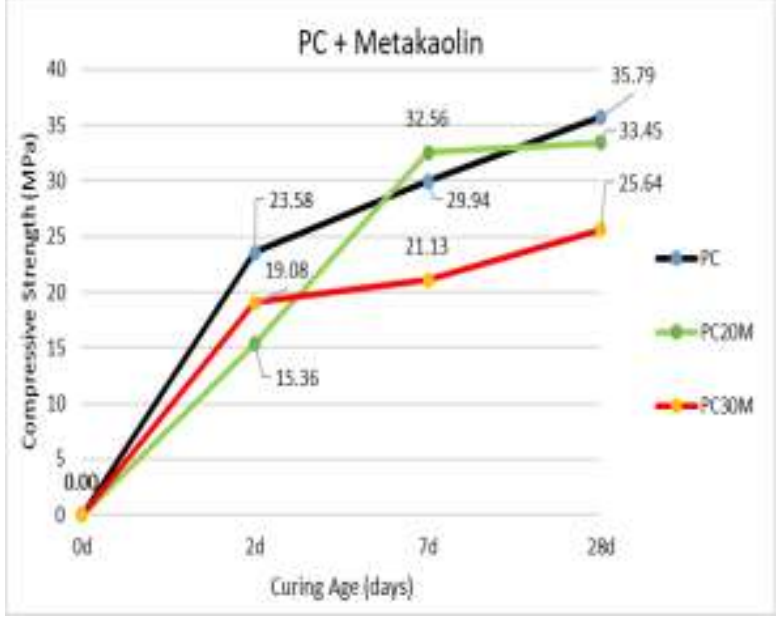

Fig. 3a Compressive Strength of PC and Metakaolin at $2,7,28$

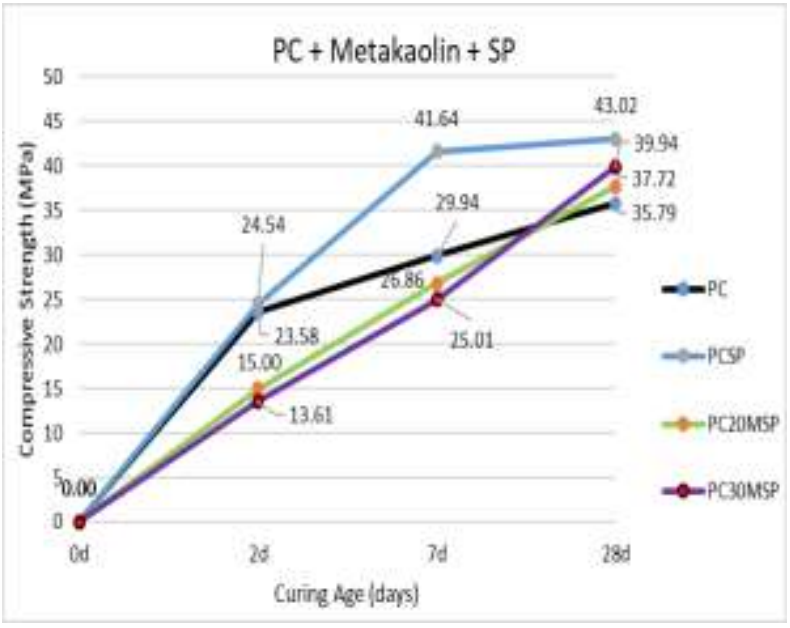

Fig. 3b Compressive Strength of PC and Metakaolin at $2,7,28$ days

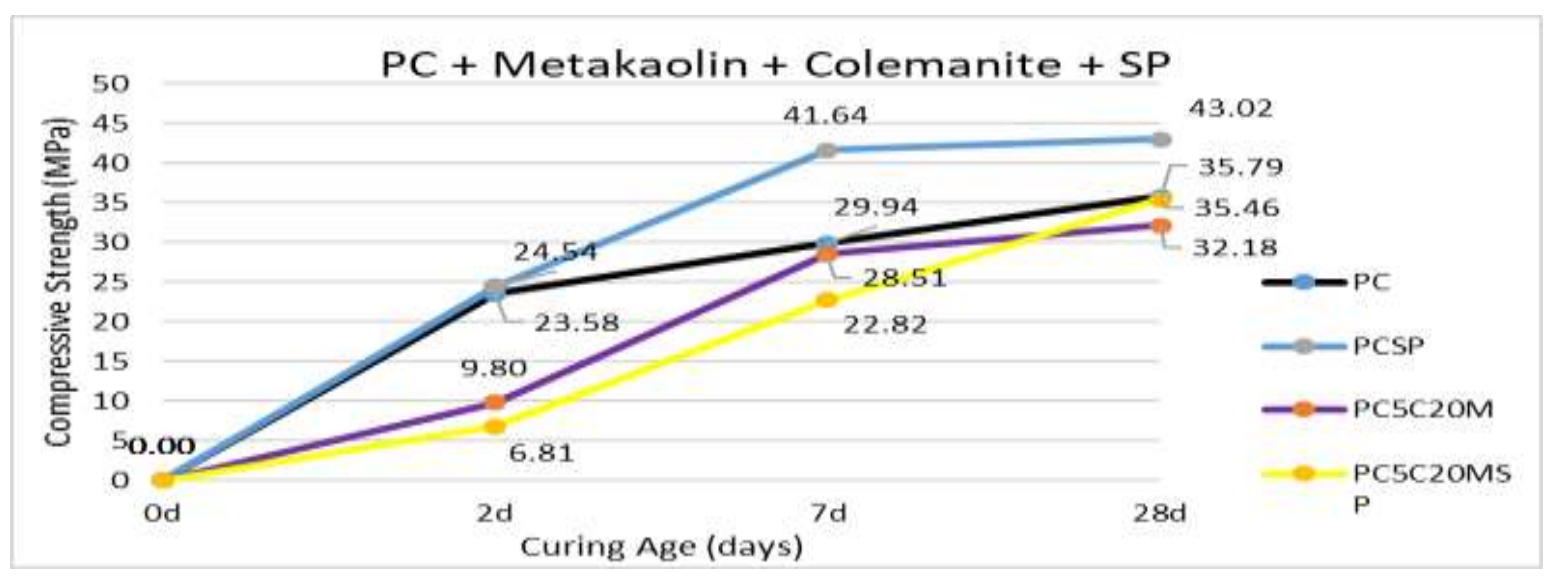

Fig. 4 Compressive Strength of PC, Metakaolin, Colemanite and SP at 2, 7, 28 days 
Table 4. Compressive strength test results at different curing ages

\begin{tabular}{|c|c|c|c|c|c|c|c|}
\hline \multirow{2}{*}{ Mix ID. } & \multirow{2}{*}{ Description } & \multicolumn{3}{|c|}{ Compressive strength (MPa) } & \multicolumn{3}{|c|}{ Flexural strength (MPa) } \\
\hline & & 2 Days & 7 Days & 28 Days & 2 Days & 7 Days & 28 Days \\
\hline PC & $100 \% \mathrm{OPC}$ & 23.58 & 29.94 & 35.79 & 5.95 & 7.1 & 8.03 \\
\hline PC5C & $95 \% \mathrm{OPC} 5 \% \mathrm{C}$ & 13.6 & 17.3 & 25.3 & 3.72 & 5.31 & 6.19 \\
\hline PC7C & $93 \% \mathrm{OPC} 7 \% \mathrm{C}$ & 8.55 & 16.07 & 20.34 & 2.62 & 4.3 & 6.13 \\
\hline PCSP & $100 \% \mathrm{OPC} 1 \% \mathrm{SP}$ & 24.54 & 41.64 & 43.02 & 6.37 & 9.45 & 9.72 \\
\hline PC5CSP & $95 \% \mathrm{OPC} 5 \% \mathrm{C} 1 \% \mathrm{SP}$ & 12.71 & 32.68 & 38.71 & 3.78 & 7.49 & 7.76 \\
\hline PC7CSP & $93 \% \mathrm{OPC} 7 \% \mathrm{C} 1 \% \mathrm{SP}$ & 0 & 25.44 & 35.31 & 0 & 7.15 & 8.5 \\
\hline PC20M & $80 \% \mathrm{OPC} 20 \% \mathrm{MK}$ & 15.36 & 32.56 & 33.45 & 5.2 & 7.8 & 8.83 \\
\hline РC30M & 70\%ОРC30\%MK & 19.08 & 21.13 & 25.64 & 5.13 & 5.79 & 7.75 \\
\hline PC20MSP & $80 \% \mathrm{OPC} 20 \% \mathrm{MK} 1 \% \mathrm{SP}$ & 15 & 26.86 & 37.72 & 4.86 & 7.67 & 8.71 \\
\hline PC30MSP & 70\%ОРC30\%MK1\%SP & 13.61 & 25.01 & 39.94 & 4.4 & 6.37 & 9.27 \\
\hline PC5C20M & $75 \%$ OPC $5 \% \mathrm{C} 20 \% \mathrm{MK}$ & 9.8 & 28.51 & 32.18 & 2.7 & 6.51 & 9.41 \\
\hline PC5C20MSP & 75\%OPC5\%C20\%MK1\%SP & 6.81 & 22.82 & 35.46 & 2.3 & 5.9 & 9.34 \\
\hline
\end{tabular}

\section{2. $\quad$ Flexural Strength Test Results}

Flexural strength characteristics in tabular form is provided on (Table-7) and (Table-8). Three points loading test conducted in compliance with described in BS EN 196-1 [7]. Flexural strength of samples with 1\% addition of Polydos TS14 showed better performance over the rest of the mixes, notable that results of PC5C20M, PC20M and PC5C20MSP, PC20MSP are close. Explicit graphs are demonstrating changes in flexural strength development over 2, 7 and 28 days of curing. For a better comparison, results presented as bar chart format divided on mixes without chemical supplement Fig. 5 and including it Fig. 6. 


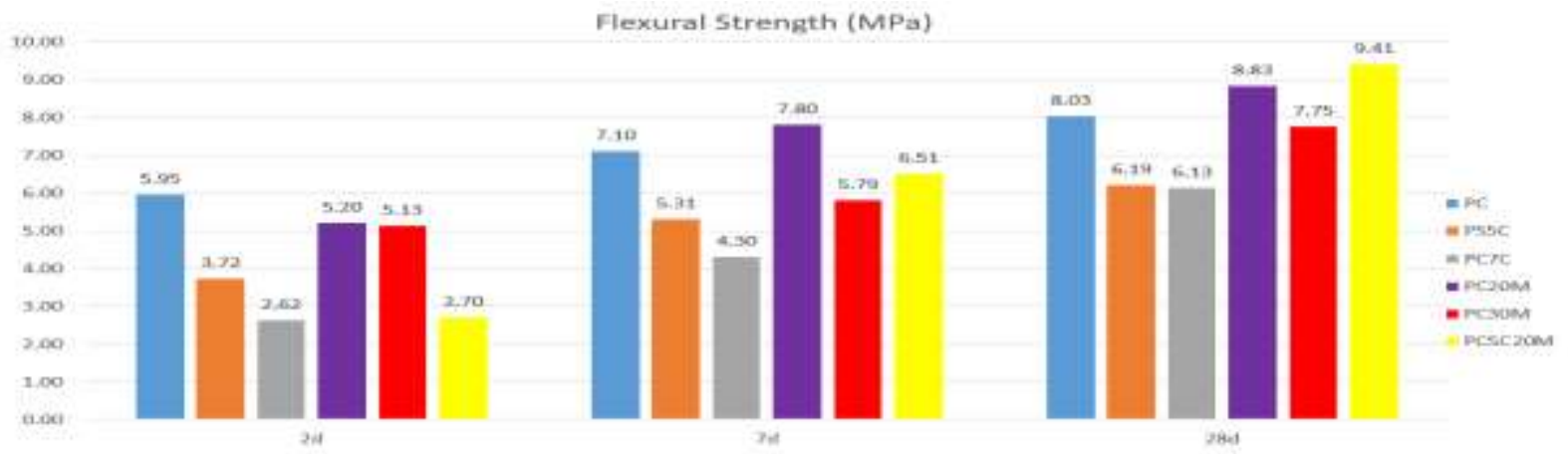

Fig. 5 Flexural Strength (MPa)

On Fig. 6 results of the same batches with addition of $1 \%$ TS14.

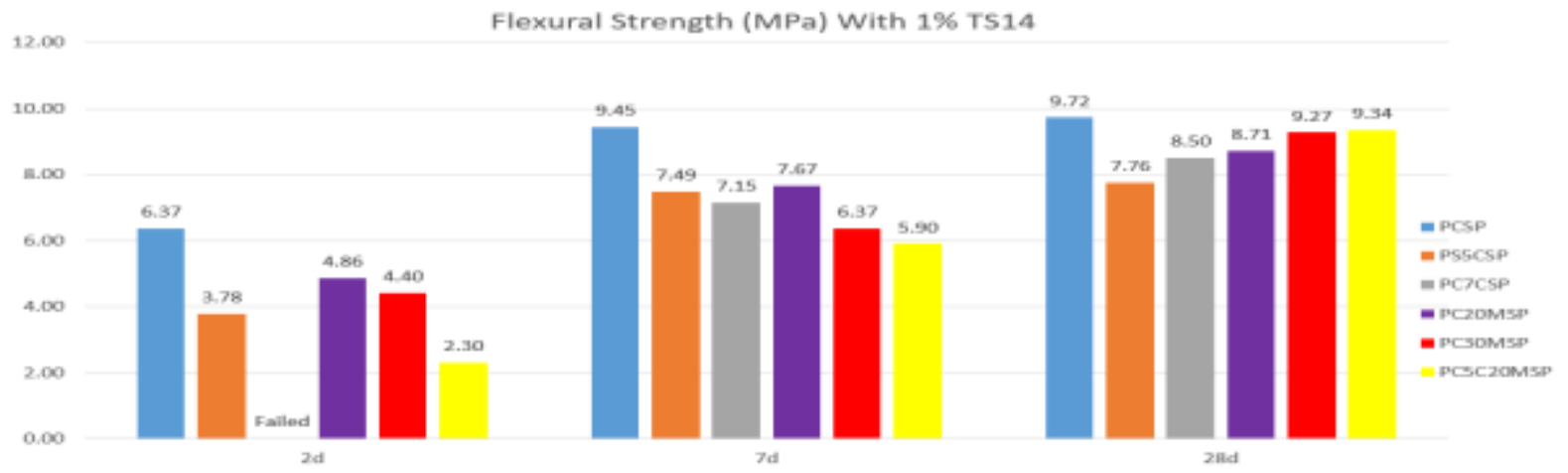

Fig. 6 Flexural Strength with $1 \%$ SP (MPa)

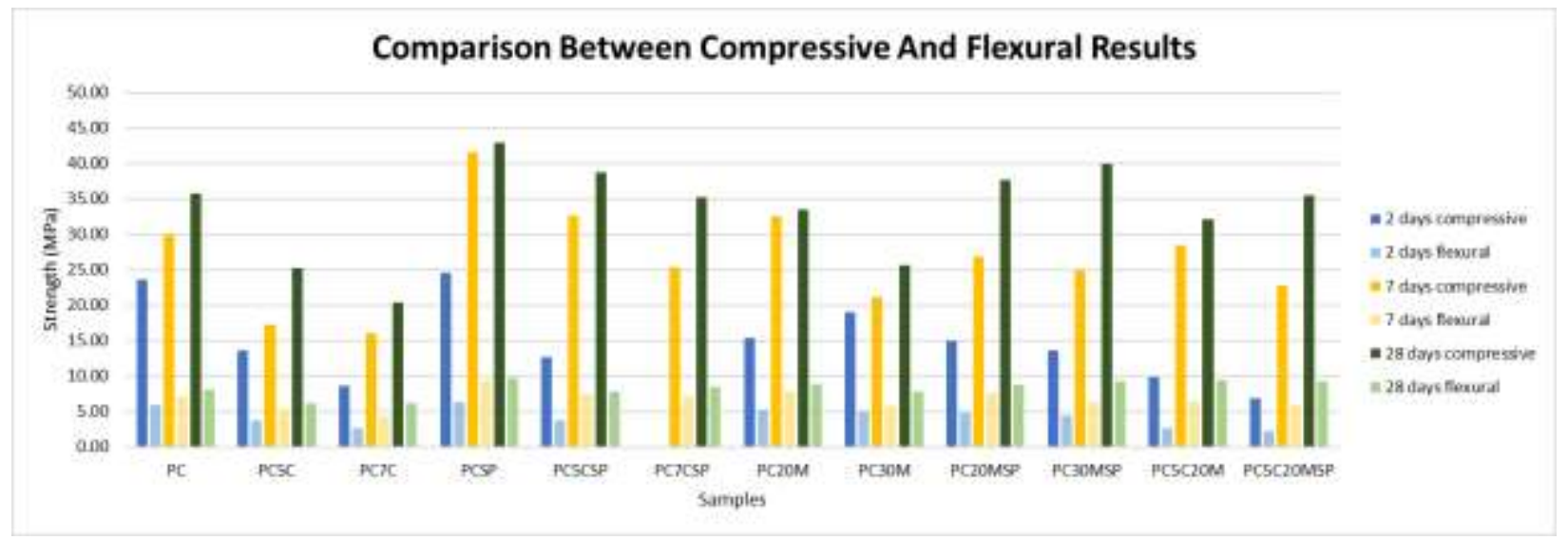

Fig. 7 Comparison between compressive and flexural results (MPa) 
Notable, that flexural strength of sample PC7CSP is higher than flexural strength of reference mix, 8.50 MPa against 8.03 MPa. The combined mix PC5C20MSP ratio showed $16.32 \%$ increase in flexural strength.

\section{CONCLUSION}

- Properties, such a compressive strength and flexural strength containing different amount of colemanite, metakaolin and Polydos TS14 have been investigated. Results obtained from testing reference mix are 35.8 $\mathrm{MPa}$ compressive and 8MPa flexural.

- Mixes with low amount of colemanite showed decrease in both compressive and flexural strength. In case of $5 \%$ substitution compressive strength decreased on $29.32 \%$ and flexural on $22.86 \%$. Use of $7 \%$ replacement severely deteriorated mechanical properties by $43.16 \%$ compressive and $23.67 \%$ flexural.

- Replacement by $20 \%$ metakaolin resulted in negligible decrease in strength to $35.4 \mathrm{MPa}$, or $-6.56 \%$. Water/cement ratio of PC20M batch is 0.5 . Replacement of cement by $30 \%$ metakaolin reduced almost $29 \%$ of compressive, and $3.43 \%$ flexural strength.

- Use of super plasticizing agent at amount of $1 \%$ improved strength of reference mix on $20.2 \%$ to $43.0 \mathrm{MPa}$. It was observed that by substituting cement by $20 \%$ metakaolin and $5 \%$ colemanite with $1 \%$ addition of Polydos TS 14 provides compressive strength result almost the same as reference value. Water/cement ratio for both experimental and control mix is 0.5 .

- Compressive strength of PC5C20MSP is $35.45 \mathrm{MPa}$ or $4 \%$ lower than reference value, flexural strength of mix has shown +16.32 improvement to $9.3 \mathrm{MPa}$. Also, total amount of cement in mortar can be reduced by $25 \%$, this provides financial and ecological benefits.

\section{REFERENCES}

1. BS EN 197 Cement Part 1: Composition, specifications and conformity criteria for common cements. 2015

2. S. Targan, Y. Erdogan, O.Gencel, U. Avciata, "Influence of colemanite admixture on Portland cement durability”, BU, DU, CBU, YTU, Turkey, 2011.

3. I. Kula, A. Olgun, Y. Erdogan, V. Sevinc, "Effects of colemanite waste, cool bottom ash, and fly ash on the properties of cement”, CBU, DU, SU, Turkey, 2000.

4. Polydos TS 14 Bayındırlık Bakanlığı Poz No: 04.613/1-A3

5. P.H. Kemp, “The Chemistry of Borax”, Part 1. Borax Consolidated Limited, S.W.I., London, 1956.

6. Gruber, K. A., and Sarkar, S. L., 1996, "Exploring the Pozzolanic Activity of High Reactivity Metakaolin," World Cement, V. 27, No. 2

7. BS EN 196-1 Methods of testing cement - Part 1: Determination of strength. 2005

8. Ş. Targan, A. Olgun, Y. Erdogan, V. Sevinc, "Influence of natural pozzolan, colemanite ore waste, bottom ash, and fly ash on the properties of Portland cement", CBU, DU, SU, Turkey, 2003.

9. M. Narmatha1, Dr. T.Felixkala, "Analysis the Mechanical Properties of Metakaolin using as a Partial Replacement of Cement in Concrete”, Educational Research Institute University, Chennai, India, 2017

10. Hooton, R. D.; Gruber, K.; and Boddy, A., 1997, "The Chloride Penetration Resistance of Concrete Containing High-Reactivity Metakaolin," Proceedings of a PCI/FHWA International Symposium on HighPerformance Concrete, New Orleans, La., pp. 172-183 